\title{
Matters of Change: Nurse Educators' Experiences Transitioning to a New Curriculum: A Qualitative Approach
}

Sarah Balcom

University of New Brunswick, sarah.balcom@unb.ca

Janet Lynne Kuhnke

Cape Breton Universty, janet_kuhnke@cbu.ca

Lilla Roy

Cape Breton University, lilla_roy@cbu.ca

Follow this and additional works at: https://qane-afi.casn.ca/journal

Part of the Adult and Continuing Education Commons, Curriculum and Instruction Commons, Nursing Administration Commons, and the Scholarship of Teaching and Learning Commons

\section{Recommended Citation}

Balcom, Sarah; Kuhnke, Janet Lynne; and Roy, Lilla (2021) "Matters of Change: Nurse Educators' Experiences Transitioning to a New Curriculum: A Qualitative Approach," Quality Advancement in Nursing Education - Avancées en formation infirmière: Vol. 7: Iss. 2, Article 9.

DOI: https://doi.org/10.17483/2368-6669.1261

This Article is brought to you for free and open access by Quality Advancement in Nursing Education - Avancées en formation infirmière. It has been accepted for inclusion in Quality Advancement in Nursing Education - Avancées en formation infirmière by an authorized editor of Quality Advancement in Nursing Education - Avancées en formation infirmière. 
Matters of Change: Nurse Educators' Experiences Transitioning to a New Curriculum: A Qualitative Approach

Cover Page Footnote

None 


\section{Background to the Study}

Nurse educators ${ }^{1}$ aim to prepare baccalaureate nursing students (through baccalaureate nursing [BN/BScN] programs) to provide "competent, safe, compassionate and ethical practice and enable them to achieve the entry-to-practice competencies expected of new graduates" (Canadian Nurses Association [CNA], 2015, p. 11). Nursing literature predicts practice settings will become more complex as they evolve to meet today's health challenges, and many nurse educators argue this process requires a transformation in nursing education (Benner et al., 2009). The current literature illustrates concept-based curricula may benefit students' learning in several ways. Baron (2017) and Goodman (2014) argued that concept-based curricula teach students to transfer knowledge between a variety of situations and client populations, which is important for future registered nurses (RNs). Repsha et al. (2020) found that concept-based curricula promoted student-centred learning and teaching and streamlining of material. Furthermore, nurse educators argue that this approach may better prepare nursing graduates for their chosen profession than traditional curricula, which organize content by topics or practice areas (Allen, 2013; Goodman, 2014). As well, concept-based curricula have been suggested as a potential alternative to traditional curricula, which are often criticized for being content-saturated (Bouchaud et al., 2017; Giddens et al., 2008).

Concept-based curricula are based on constructivist teaching and learning paradigms and shift the focus from organizing nursing topics into courses focused on particular practice areas, such as family, maternity, or medical/surgical nursing (Baysen \& Silman, 2007). For example, in a traditional nursing curriculum, students may learn about topics such as myocardial infarction or heart failure in a medical and surgical practice setting. In a concept-based curriculum, students learn about content through broader concepts such as perfusion or oxygenation, which have wider applications for patient care across practice areas and across patients' lifespans. Furthermore, students learn to interrelate concepts such as stress and family dynamics alongside perfusion and oxygenation, leading to delivery of holistic nursing care (CNA, 2013).

Nurse educators teaching a traditional curriculum who transition to a concept-based approach often need to adjust their current educational practices; such changes can be challenging. A growing body of literature describes the nurse educators' experiences in the process of implementing newly adopted concept-based baccalaureate nursing curricula (Baron, 2017; Brady et al., 2008; Deane, 2017; Giddens et al., 2015; Repsha et al., 2020). A greater understanding of nurse educators' experiences may demonstrate how educators can be further supported through program transitions. Therefore, this study sought to explore nurse educators' perspectives of change during the transition to and implementation of a concept-based curriculum in an eastern English-speaking Canadian university.

\section{Context}

Five key changes simultaneously occurred in this institution during this curricular transition. First, the overall traditional $\mathrm{BScN}$ program (eight semesters over four years) was shortened. In the traditional program, learners followed a four-year undergraduate program, completing eight semesters (semesters were 13 weeks long) over the four years (see Table 1). In the new concept-based curriculum, learners completed eight semesters over three years. Second, the theory courses and nursing practice hours shifted from being taught alongside each other over

\footnotetext{
${ }^{1}$ Nurse educators include full-time faculty (tenured and tenure-track hires) and nursing practice educators.
} 
the course of a semester to being taught in a condensed block format. For example, nursing practice typically occurred Monday and Tuesday, and theory courses were delivered Wednesday to Friday. However, in the new concept-based program, during most semesters, students experienced a block of theory courses, followed by a scheduled block of nursing practice hours.

\section{Table 1}

Comparison of Traditional Versus Concept-Based BScN Program

\begin{tabular}{|c|c|c|c|c|}
\hline \multirow[t]{2}{*}{ Timeline } & \multicolumn{2}{|c|}{ Traditional } & \multicolumn{2}{|c|}{ Concept-based } \\
\hline & Theory & $\begin{array}{l}\text { Nursing } \\
\text { Practice }\end{array}$ & Theory & $\begin{array}{l}\text { Nursing } \\
\text { Practice }\end{array}$ \\
\hline Sept-Dec & $\begin{array}{l}\text { Semester } 1 \\
\text { Semester } 3 \\
\text { Semester } 5 \\
\text { Semester } 7\end{array}$ & $\begin{array}{l}\text { Nursing practice } \\
\text { hours occur over } \\
13 \text { weeks. }\end{array}$ & $\begin{array}{l}\text { Semester } 1 \\
\text { Semester } 3 \\
\text { Semester } 6\end{array}$ & $\begin{array}{l}\text { Nursing practice } \\
\text { hours occur in } \\
\text { blocks ( } 4 \text { to } 5 \\
\text { weeks, } \\
\text { approximately). }\end{array}$ \\
\hline Jan-April & $\begin{array}{l}\text { Semester } 2 \\
\text { Semester } 4 \\
\text { Semester } 6 \\
\text { Semester } 8- \\
\text { Graduation }\end{array}$ & & $\begin{array}{l}\text { Semester } 2 \\
\text { Semester } 4 \\
\text { Semester } 7\end{array}$ & \\
\hline May-August & & & $\begin{array}{l}\text { Semester } 5 \\
\text { Semester } 8 \text { - } \\
\text { Graduation }\end{array}$ & \\
\hline
\end{tabular}

Third, the community of learners (students) changed as the concept-based program expanded to include more licensed practical nurses and advanced standing students (i.e., learners with existing university credits). Increasing numbers of learners entered the program with more diverse life experiences, requiring the nurse educators to adapt and modify their educational approaches. Fourth, transition to a concept-based curriculum included an overlapping period during which nurse educators were phasing out the traditional $\mathrm{BScN}$ curriculum, while at the same time educators were beginning to implement the newly developed concept-based curriculum. For nurse educators, this meant they may have been teaching in the traditional and concept-based curricula at the same time. Finally, the transition to concept-based learning included two changes in textbooks and associated-teaching resources. For the first cohort of learners, the curriculum committee adopted two concept-based textbooks, but for the second cohort of learners, an online textbook package from a different publisher was adopted.

\section{Purpose}

The aim of this study was to explore nurse educators' perceptions of change as they transitioned from a traditional baccalaureate $\mathrm{BScN}$ program to a concept-based curriculum. 


\section{Method}

\section{Design}

A qualitative descriptive design with individual interviews was used (Sandelowski, 2010). A qualitative descriptive design is flexible and permits researchers to select from a variety of different approaches regarding sampling, data collection, analysis, and question guide development (Haegele et al., 2020).

Although the purpose of qualitative descriptive design is to summarize events and keep the data as close to the participants' experiences as possible, some interpretation is permitted (Sandelowski, 2010). The researchers carefully developed an interview guide to ensure that the same questions were used with each participant. The interview guide questions were designed to encourage the participants to look inward and reflect on the meaning of their experiences transitioning to the newly adopted concept-based curriculum (see Table 2) (Creswell, 2003, 2007). Interview questions were first tested with a volunteer nurse educator who was not in the study. Interviews were voluntarily completed 12 months after the first cohort of students were enrolled in the new concept-based curriculum. This design enabled the researchers to capture nurse educators' individual experiences.

Table 2

Interview Schedule Questions

Nurse Educator Interview Guiding Questions (Creswell, 2003, 2007)

Situating self-preparation for concept-based curriculum

"What is your perception of how well you were prepared for concept-based teaching?"

Probing questions might include: How do you perceive you could have been better prepared?

Situating self-learning concept-based curriculum

"We know we are on a journey of learning about concept-based teaching. Where do you perceive yourself to be on this journey?"

Probing questions might include: Rate on a scale from 1 to 10 their perspective of being novice to expert

(Benner, 1982).

Situating self-thinking pattern

"How do you perceive your present thinking has changed from topic-based teaching to concept-based teaching?"

Probing questions might include: Do you still translate "language" from topic-based to concept-based lectures/ notes/language?"

Linking concepts

"How do you perceive your students link concepts to clinical scenarios/ exemplars/practice? Provide examples."

"How do you perceive your students approach scenarios they have not seen before? How are they making conceptual links, or are they?"

"How do you find these students approach patients/ scenarios compared to previous students?"

Probing questions might include: Provide examples of how you discuss concepts in situations that your students have not seen before.

Teaching experience

"Can you tell us whether/how a concept-based curriculum has changed the 'content saturation' of your courses?" 


\section{Participants}

Fourteen nurse educators from an eastern Canadian English-speaking university were invited to participate in one-on-one interviews with a nurse educator who was new to the $\mathrm{BScN}$ program. These nurse educators were purposively recruited (Creswell, 2007). Information related to the nurse educators' teaching history and demographics was collected.

\section{Framework}

Bridges's (2009) transitions framework underpinned the entire study design. This framework recognizes that in any change, there is also a personal journey of transition. The transitions framework includes the following phases: in endings, shock, anger, denial, and fear occur; in the neutral zone, people may be less productive, feel confusion, disorientation, and frustration, and may experience skepticism and be apathetic; finally, the third phase includes feelings of excitement, energy, and commitment to the new processes. Again, the interview guide questions were designed to encourage participants to reflect on this inward journey.

Bridges's (2009) framework emphasized change as the circumstances in which the educators find themselves and transitions as the psychological processing that occurs when one experiences change. When in transition, people may identify with, and come to understand, the inner psychological processes experienced during transition and change (Bridges \& Mitchell, 2000). Therefore, this study focused on the exploration of nurse educators' perspectives of their inner journeys rather than of the implementation process itself.

\section{Analysis}

Audio recordings were taped with consent, anonymized, and transcribed verbatim; data were read, reread, and thematically analyzed (Braun \& Clarke, 2013). NVivo 12 was used to aid in the analysis (QRS International, 2018). Thematic analysis provided the opportunity for findings to be qualified rather than simply reported, allowing subtleties, patterns, and themes to emerge (Miles et al., 2014).

\section{Validity}

Two researchers analyzed the data and the third researcher reread and re-themed the data. Researchers kept clear documentation of procedural and interpretive decisions, as well as reflexivity journals. ${ }^{2}$

\section{Ethics}

Ethics approval was obtained from the university's research ethics board.

\section{Findings}

\section{Participants}

Six female participants voluntarily engaged in the interview process (see Table 3). Of the participants, five taught for over 11 years. Two participants previously taught in another baccalaureate nursing program. Five had recently taught concept-based theory courses, three taught concept-based nursing practice, and two taught in both. As well, three participants taught in the first semesters of the new concept-based program. To the nearest minute, the average

\footnotetext{
${ }^{2}$ Reflexivity journals "emphasi[ze] the reflective nature of social [and work] life" while engaged in the study (Denzin \& Lincoln, 2011, p. 591).
} 
duration of all six interviews was 34 minutes. The names used in this article are pseudonyms chosen by the researchers to keep the participants' identities confidential.

\section{Table 3}

Participant Information

\begin{tabular}{lc}
\hline Participant teaching and demographic information & $N=6$ \\
\hline
\end{tabular}

Gender

$\begin{array}{ll}\text { Female } & 6 \\ \text { Male } & 0 \\ \text { Other } & 0\end{array}$

Preferred language

$\begin{array}{lr}\text { English } & 6 \\ \text { French } & 0 \\ \text { Other } & 0\end{array}$

Teaching years

$0-5$

6-10

$>11$

Experience teaching elsewhere

$\begin{array}{ll}\text { No } & 4 \\ \text { Yes } & 2\end{array}$

Terms teaching the concept-based curriculum (CBC)

Term 3

Term 4

Term 5

2

Term 6

3

Term 7

Types of courses taught

Clinical courses 3

Theory courses $\quad 5$

Both 2

Rank

Faculty 4

Nurse practice educator $\quad 2$

Recent overload (within the last year)

$\begin{array}{ll}\text { No } & 1 \\ \text { Yes } & 5\end{array}$

\section{Thematic Analysis}

Four key themes emerged from the data: personal self-efficacy-finding confidence and belief in one's ability to succeed through change; personal challenges-remaining committed while moving away from the familiar, progressing forward, hoping for positive results, and making adjustments as needed; personal learning — needing time for personal learning, to translate theory into practice, and to reorganize; and finally, navigating the experience of change-knowing change is both exciting and daunting. Participants were very committed to this curricular change. Throughout the interviews and analysis, researchers perceived an underlying and pervasive optimism toward the innovative curricular change. 


\section{Personal Self-Efficacy}

Varying Levels of Self-Efficacy. Participants described varying levels of self-efficacy ${ }^{3}$ throughout the development and implementation of the new concept-based $\mathrm{BScN}$ program. They described initial uncertainty in their ability to continue to facilitate learner-focused activities in the classroom, lab, or nursing practice setting while also learning to teach using concept-based principles. Participants used words such as beginner, novice, and advanced-beginner to describe their ability to understand and implement concept-based teaching (Benner, 1982). When asked to rate themselves on a scale of 0 (no confidence) to 10 (very confident), participants rated themselves from novice and growing. This contrasts with their descriptions of self-identifying as competent, confident, expert nurse educators. In these descriptions, they described growing optimism that they would become more confident over time and with additional supports.

Dawn ${ }^{4}$ was uncertain when seeking to find nursing information within the newly adopted process of using online concept-based textbooks and resources. She stated:

It is unbelievably overwhelming even from my perspective. I don't have things in a central location, I am teaching a concept and a couple of exemplars, ${ }^{5}$ and [in doing so] I am accessing six and seven online textbooks, which demands my students do the same. It is overwhelming... I do say to them okay, focus on this one [concept], but you need to go at least to the med-surg, [then to the] mental health books for this one, and then [to the] maternal-child health books for this [other exemplar]; it is not centrally located.

Dawn further elaborated, "To teach it [nursing] from a concept perspective, I don't feel like I have been prepared adequately at all to do this, though I know it takes time."

Frances described her perspective as vacillating and uncertain. Specifically, she felt unsure in whether students were getting sufficient direction within the new concept-based approach. She regularly asked herself the following:

Do I know whether I am doing a good job? I don't know. Do I feel like I have the student's attention and do I feel they are getting some of the information? Maybe! But I have never had the confidence and feel like I am giving them everything they need. And I don't know if you ever get that feeling... [She paused.] No, when I reflect, I did not have it in the [traditional nursing program] either; maybe it is not something to seek.

Erin was able to rely on past experience in problem-based learning to support her understanding of the new concept-based approach. However, she also described a disquiet within as she adapted to the new program resources. She articulated the following:

I think I was well prepared to do it. I had done a lot of research. I actually think that probably when I did my initial [nursing] degree program, it was problem-oriented, which was kind of like a concept-based curriculum. So, it was kind of going back to my roots in some ways... I think more of my issues were around the learning resources; that is where the discomfort was... it was getting use[d] to some of the [online textbooks]... we went

\footnotetext{
${ }^{3}$ Self-efficacy is the "belief that one can achieve what one sets out to do-[people with high self-efficacy] are healthier, more effective, and generally more successful than those with low self-efficacy expectancies" (APA PsychNet, 2019, para, 1).

${ }^{4}$ Transcripts were edited for clarity (Braun \& Clarke, 2013).

${ }^{5}$ An exemplar is an example of a concept; for example, when teaching perfusion, one would teach heart failure as an exemplar.
} 
with... [one] textbook last year and the learning resources around that [book], there was discomfort... so I think always when there is a change there is always unease.

Participants did not generally describe high self-confidence in transferring their previous/familiar teaching abilities, knowledge, and skills from the traditional program to the new concept-based program.

\section{Remaining Committed and Moving from the Familiar}

Comparing Programs to Make Sense of the Changes. Participants described feeling distressed when moving from familiar workloads in a well-established and successful curriculum to the less-familiar context of the new concept-based curriculum. In the interviews, participants regularly compared the traditional program to the new program. By identifying differences, they sought to make sense of change while immersed in the demands of implementation. Erin describes an example of trying to cognitively map ${ }^{6}$ forward her known knowledge and skill level into the new concept-based program. These changes include her recognizing that there are now different course requirements and learners with diverse backgrounds. ${ }^{7}$ She recounts the following:

So, it is important that you do cover some key stuff. You can't leave it all too independent learning. I will give you an example. In one term, one of the concepts is "development" and I can't help but compare it to the old program. In the old program they have four psychology courses [which cover development] and this program, if they came to [our university] they get one psychology course, but they could have gotten into the program without any psychology courses... so to introduce the concept of development [where you need to] do all of the ages and stages, that was [all] one concept [taught in one class].

When participants described change processes and associated feelings, they consistently verbalized their strong sense of resilience, ${ }^{8}$ hope, and commitment to implementing the new program. They described a high level of commitment to the new program and to the many changes they incurred. They regularly described angst over change and compared the traditional and known to the new and less known. These feelings are depicted in Figure 1 (Field note, November 2018). This drawing is from one of the researcher's field notes. Participants first saw it when they were shown a draft of this article for member checking. Most participants reported that the drawing depicted their feelings as a group during the interviews and how they were "in it together." They hoped it would be left in future drafts.

\footnotetext{
6 A cognitive map is a representative expression of an individual's cognitive map knowledge. Cognitive map knowledge is an individual's knowledge about the spatial and environmental relations of geographic space (Smelser \& Baltes, 2001).

${ }^{7}$ More students were admitted to the $\mathrm{BScN}$ program with previous university and college education.

${ }^{8}$ Resilience as a concept is described as a process where people "bounce back from adversity and go on with their [work lives]. It is a dynamic process highly influenced by protective factors." This includes competencies and "healthy skills and abilities that the individual can access and may occur within the individual or the interpersonal or family environment" (Dyer \& McGuinness, 1996, p. 276).
} 
Figure 1

Participants Describe the Cognitive Back and Forth During the Change and Transition

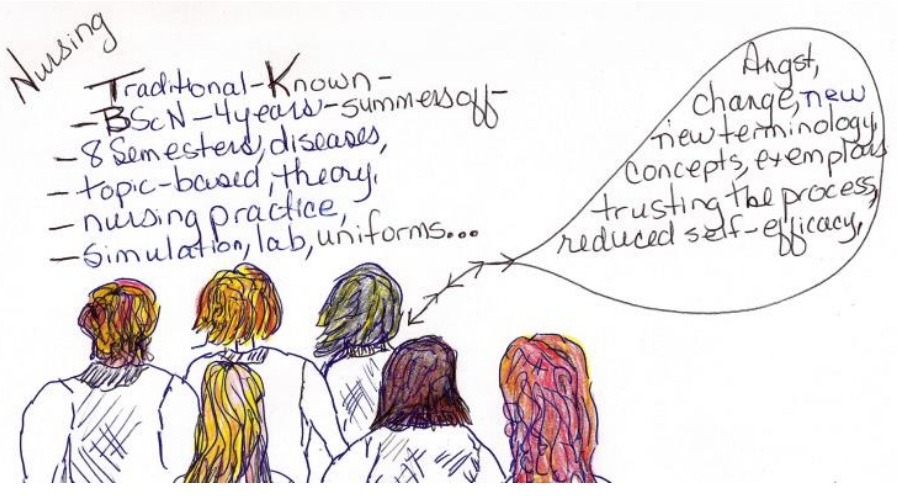

\section{Time Needed to Be a Learner}

Time Needed for Personal Learning. While adopting the concept-based curriculum, participants described the role of being a learner while continuing to complete their present workload. They explained how they were self-studying to master concept-based educational principles. They described sharing resources with peers, such as articles and teaching strategies relevant to concept-based teaching in both theory-based courses and the nursing practice setting. They self-directed their learning and read relevant articles, accessed online resources, and participated in workshops and webinars. Beth explained how she immersed herself in the literature to learn and move forward:

Well, [I did] a lot of reading and research on concept-based curriculum. There was a lot of information sent out through the department from the [curriculum] committee: current practices [were discussed as a group], [we talked about] how universities were doing concept-based curriculum, and there were webinars available.

Most participants felt they had the time to learn what was needed to achieve a sense of competency in relation to concept-based educational approaches. Ashley described the need for more time to learn:

I would like there to have been a lot more time given to utilize the information we had been given... So yes, we have been given information, but the fact that we were teaching the old program and trying to get ready to embark on this [new program] in such a short period of time, I don't feel that I had enough time to prepare, although I was given tools.

Angst While Transitioning to New Technologies and Resources. Participants understood that the shift to concept-based teaching required a considerable amount of independent learning and recognized the need for learning supports for curriculum technologies and resources to be available. Erin described the importance of consistent and reliable learning platform support and acknowledged that any change in learning resources or technologies creates a new stressor. When leaving familiar learning technologies, she talked about how she felt like a novice and that switching different resources meant it "created much more angst because of her steep learning curve." 
Time to Translate Theory into Practice. In the context of lab, simulation, and nursing practice, the question of implementing concept-based teaching approaches was particularly uncomfortable. Participants described the tension of translating theory into practice without time to see it, try it, or learn it slowly. For example, Frances asked: "How do you translate a concept such as cellular regulation or thermoregulation, or the lifespan approach, into practice-based activities?" Ashley outlined the following: "We had lots of information, but then how do you actually do it? We read lots of articles, we were given lots of articles on the whys, but there wasn't a lot on the how; I just needed more time to process the changes occurring."

Time Needed to Reorganize. Participants were learners and educators at the same time. As the curriculum change included a move to block teaching, ${ }^{9}$ participants discussed the need to reorganize their approach to grading care plans or papers to provide learners with timely and relevant feedback. For example, an assignment completed on a Wednesday or Thursday session (for example, the first paragraph of a research paper), may need to be returned early in the next week to move the assignment forward. Erin explained the following: "It is our time frame. It is very fast; the turnaround is fast. I had one assignment in my course and [had] to correct 71 assignments and get them back so that they could learn from them."

\section{Navigating Change: The Experience of Change}

Disquiet With Unforeseen Circumstances. Participants described the challenge of change and their perception of loss of control. They described feelings of powerlessness during the change process, though they qualified this by acknowledging that these feelings were normal for experienced nurses. They described that when unseen circumstances arose that required further change, this led to increased feelings of doubt, unease, and uncertainty. Erin expressed how the anticipated plan was not "rolling out" as she had envisioned. Erin described that "when we designed the program initially, it was with the idea that we would be team teaching; ${ }^{10}$ now that we are not [team teaching], do we need to revisit [the overall plan]?" For Erin, this creates uncertainty. Then she described another change with a new textbook being used. She described the struggle with back-to-back changes. She elaborated with the following:

Well, what happened was because we changed textbooks there was a belief that we should put our concepts in line with the textbook, which I don't really agree with. But that is just one person. So anyway, our concepts got changed again to go with the new textbook, it was stressful.

\section{Discussion}

The participants described the experience of transitioning from a well-established $\mathrm{BScN}$ curriculum to a new concept-based curriculum as challenging; the change caused a major shift in their identity and workload. This study found that curricular changes influenced educators' sense of self and their self-identities. As well, the educators verbalized a pulling-forward of expertise and experiences from previous nursing work. There is an unspoken enduring resilience, and they were hopeful, optimistic, and committed to the change being successful.

\footnotetext{
${ }^{9}$ Block teaching is a style of teaching where "lectures, tutorials and other forms of teaching are provided in an intensive block [from one to seven weeks]... and student learning is compressed" (King \& Craik, 2019, para 3). ${ }^{10}$ In team teaching, for example, a nurse specialized in mental health might teach the mental health concepts across the program, rather than teaching multiple concepts that they may not be specialized in.
} 


\section{Personal Self-Identity as an Educator}

Nurses often derive their identity from both their work environment and values (ten Hoeve et al., 2014). In this study, the nurse educators described how their identities shifted from their "known" identities of being "competent" teachers in a traditional BScN program to being novice teachers in a concept-based nursing program. The nurse educators frequently talked about their identities in terms of their self-efficacy, ${ }^{11}$ using words like novice or competent/expert). Consequently, it became important to discuss their self-efficacy as both a cause and a consequence of their learning processes, and to consider their perceptions of their self-efficacy over time (Holzberger et al., 2013).

The participants' description of their self-efficacy shifted from feeling "competent" and "expert" toward being a "novice." This occurred in both theory and practice courses. How the participants' described their self-efficacy reflected a deeper-seated understanding that emphasized the relationship between their confidence and their ability to problem solve (Gobet \& Chassy, 2008, p. 129). Previous research demonstrated that teachers' identity is a key "factor for the effectiveness of the teaching activity, as it is a powerful drive influencing the behaviour of teachers in the classroom and the effort put in the endeavor[s]" before them (Barni et al., 2019, p. 4). Recognizing the potential for shifts in self-efficacy during a curricular change can provide opportunities for change leaders to anticipate and respond to educators' heightened, ongoing needs (Holzberger et al., 2013).

The nurse educators' professional identities had to shift to adapt to the new concept-based program. Gonzalez and Monereo (2012) found nurse educators feel incredibly responsible for helping to create nursing professionals while also managing change and curricular events. Identity formation processes include both social and psychological or "ways of being" (Gonzalez \& Monereo, 2012). The conceptualization of identity includes educators' individual perception of themselves as members of a profession who have a commitment and responsibility to "society, recipients or care, other professionals, and to himself or herself" (Crigger \& Godfrey, 2014, p. 377). A disruption in this identity as a result of contextual changes within an institution or a department may significantly impact the stability of the educator's professional identity and role (McNaughton \& Billot, 2016). This is to be anticipated when change occurs (McNaughton \& Billot, 2016). This disruption of identity is echoed in the adoption of e-learning by institutions, which also requires a significant pedagogical shift from teacher-focused to learner-focused modalities (Golden, 2016; Hanson, 2009; Sword, 2012). Educators' identities are expected to be dynamic, shift over time, and be influenced by previous experiences (Beauchamp \& Thomas, 2009). Participants pulled forward strengths from their previous experience as educators and over time shifted to a new identity. Over time, they began to describe themselves as nurse educators who now "teach in a concept-based BScN program" versus a traditional BScN program.

Some researchers have identified several ways educators can be supported as they develop their professional identities throughout their careers. van Lankveld et al. (2017 identified five psychological processes that could support teachers' professional identity development within the university environment: "a sense of appreciation, a sense of connectedness, a sense of competence, a sense of commitment, and imagining a future career trajectory" (van Lankveld et al., 2017, p. 325). van Lankveld et al. (2017) argued that to "empower university teachers, it is important to

\footnotetext{
11 The concept of self-efficacy originates from Bandura's $(1977,1997)$ social cognitive theory of behavioural change.
} 
reward teaching excellence and build community" (p. 325). The also recommended administrators organize staff development activities to help teachers, both individually and collectively, develop their feelings of confidence and control in their workplaces (van Lankveld et al., 2017, p. 32). These supportive activities are important during times of significant change (Repsha et al., 2020). Hackel and Zaki (2017) suggested that a flexible social identity ${ }^{12}$ may contribute to the successful navigation of challenging situations in which a fixed identity may be limiting. Finally, educators need time to reconstruct their professional identities and "develop competencies and practice and develop ownership of the change" they are experiencing (Voogt et al., 2016, p. 121).

\section{Remaining Resilient While Moving From the Familiar}

The nurse educators' experiences could be mapped into the first and second phases of Bridges's (2009) transitions' framework (see Figure 2). Unique to this study was an enduring resilience and commitment to the success of the new program, which was apparent throughout the change/transition. Although the participants described a wide range of experiences, as modelled in each phase in Bridges's (2009) framework, they verbalized an overall commitment to preparing the students for their future careers as nurses.

The first phase of Bridges's (2009) framework was exemplified by descriptions of frustration, uncertainty, and a sense of loss of what was known. Educators were initially uncomfortable with the change before them; they experienced emotions associated with ending and letting go of a traditional teaching model. As a result, they immersed themselves in the change processes and details of course and practice development (Duffy, 2013). Educators verbalized concern that important nursing content was being "left out or lost" in the development of the concept-based curriculum, which is similar to findings by Patterson et al. (2016). Knowing these emotions will occur with change, it is important for teams and leaders to come onside with regular and open communication and empathetic listening (Miller, 2017). Miller further described this process as a time "when you need to help people deal with their losses" (p. 360).

Second, educators moved into a "neutral zone" an "in-between" phase. During this time, the educators were ending the traditional $\mathrm{BScN}$ program, all the while developing a new program of which they were skeptical, and skepticism is expected (Deane, 2017). Crawford (2014) described the phase as possibly leading to lower morale, variable productivity, and further rolerelated fear and anxiety. In this phase, guiding the team is essential so they feel productive. Miller (2017) stated that during this time, a "psychological realignment and repatterning take place" preparing educators to move forward (p. 360). Finally, as educators began to embrace the new program, they began to reconstruct a "new identity, experience the new energy, and discover a new sense of purpose that makes the change begin to work" (Bridges, 2009, pp. 4-5).

\footnotetext{
12 Social identity includes people finding themselves as part of a group and includes feeling vested in that group. Highly flexible identities may be more adaptable to change (Hackel \& Zaki, 2017).
} 


\section{Figure 2}

\section{Change and Transition Framework}

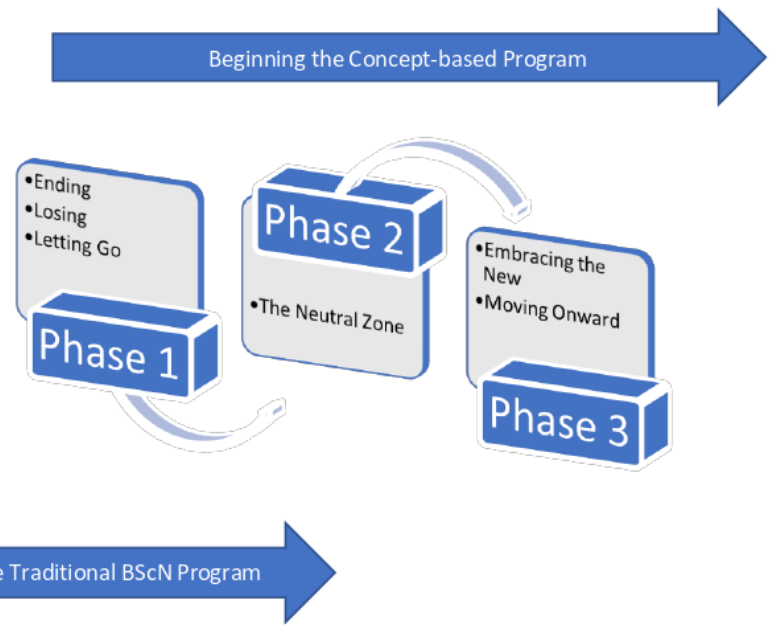

Source: Adapted from Bridges and Mitchell, 2000.

\section{Time Needed to Be a Learner}

Being in a learner and a teacher role simultaneously is challenging. When learning, educators' experiences are brought forward. Educators learn and are influenced by how they have previously learned, and this will modify how they will learn in future (Dewey, 1938, p. 35). When undergoing change, team members benefit from engaging in discussions on how other members learn (Miller, 2017; Rogers, 2003). Nurse educators, during curricular change and transition, became immersed in the learner role while carrying on full-time roles and responsibilities. Watkins (2015) stated that teachers as learners

need space to grow in practice as well as support for their failure and recovery. [A leader] or mentor who is keenly aware of ...staff and understands them as learners can promote both professional growth and practice..., [which] creates bonds of trust and collegiality missing from transactional, top-down memoranda. (p. 83).

As well, educators need time to learn the philosophical and pedagogical underpinnings of any new approach (Deane, 2017; Kantor, 2010). Sword (2012) described groups of nurses transitioning to e-learning as being worried about losing usual ways of teaching and learning, needing more resources and time to adapt, while persevering. Time was needed to explore and navigate new concept-based resources and develop theory, lab, and clinical activities. Rapid change to teaching-learning processes requires open conversation, consistent support, and team education for long-term success (Rogers, 2003). The importance of providing time to be a learner during the preparation phase of curricular transition cannot be underestimated (Baron, 2017).

\section{Supporting Nurse Educators Through Change}

A growing body of literature is calling for curricular change in nursing education. However, there is little in the literature about nurse educators' experiences through such change and more research is needed. Most literature about curricular change focuses on students' experiences or their learning outcomes (Duncan \& Schultz, 2015). Brady et al. (2008) described 
how they used Kanter's seven skills for effective change model to guide them through a transition to a concept-based curriculum. The seven skills are tuning in to the environment, challenging the prevailing organizational wisdom, communicating a compelling aspiration, building coalitions, transferring ownership to a working team, learning to persevere, and making everyone a hero (Brady et al., 2008). Brady et al. (2008) did make some recommendations for navigating curricular change which relate to the findings of this study. For example, similar to the participants of this study, Brady et al. found the timeline of concurrently launching a new curriculum and teaching out the previous curriculum challenging. Brady et al. recommended nurse educators work closely with administrators to work out necessary logistics, like reasonable workload and scheduling/timetables. Brady et al. also recommended using outside consultants to conduct faculty development sessions, which is something the participants of this study found helpful too. Finally, Brady et al. emphasized the importance of celebrating goals and milestones along the way through dinners and other team-building activities, which was something the participants of this study expressed interest in.

The participants in this study may have benefited from reflecting on their "mix of change styles" during the transition (Miller, 2017, p. 358). In Miller (2017), a change and transition team pre-screened educators to understand how they, as individuals, respond to change. They used a self-scoring instrument that aided in identifying how one perceives and adapts to change. The participants in this study may have benefited from first understanding whether they preferred a role leading or following, what their emotional expression may be, whether they were task or people focused, and whether they were open or more cautious to change (Ryan Change Style Assessment, as cited in Miller, 2017).

\section{Conclusion: Navigating Successful Change}

The educators in this study experienced change and navigated the transition to the conceptbased program in a manner reflected in the transitions' framework (Bridges, 2009). Ideally, curricular transition would be slow, allowing educators time to adapt to and adopt changes and contribute to the development of solutions, thereby encouraging acceptance over time (Duffy, 2013). It is easy to underestimate the demands and communications needed to facilitate successful change (Baron, 2017). As well, educators need consistent and "sufficient support when revising curriculum from a traditional approach to [a] concept-based" program (Baron, 2017, p. 285).

\section{Study Limitations and Recommendations}

This study reflects the perspectives of a group of educators. All the participants were actively teaching. The lead interviewer was new to the university program, and the three faculty analyzing the data regularly discussed findings while doing so. Bracketing and reflexivity activities aided in avoiding bias. To truly work alongside staff who are engaging in significant curricular change, there may be room to explore, through more research, a "pre" phase 1 of the Bridges model by identifying what would end and what would be let go. More research is needed to fully understand educators' needs through change. 


\section{References}

Allen, P. (2013). Preparing nurses for tomorrow's healthcare system. American Nurse Today, $8(5), 46-50$.

APA PsychNet. (2019). Self-efficacy defined. https://psycnet.apa.org/record/1997-08589-000

Bandura, A. (1977). Self-efficacy: Toward a unifying theory of behavioral change. Psychological Review, 84, 191-215.

Bandura, A. (1997). Self-efficacy: The exercise of control. W. H. Freeman \& Company.

Barni, D., Danioni, F., \& Benevene, P. (2019). Teachers' self-efficacy: The role of personal values and motivations for teaching. Frontiers in Psychology, 10, 1-7.

Baron, A. (2017). Changing to concept-based curricula: The process for nurse educators. The Open Journal Nursing, 11, 277-287. https://doi: 10.2174/1874434601711010277

Baysen, E., \& Silman, F. (2007). Constructivist approach. In Z. Kaya \& A. Akdemir (Eds.), Learning and teaching: Theories, approaches and models (pp. 116-132). Çözüm Publishing.

Beauchamp, C., \& Thomas, L. (2009). Understanding teacher identify: An overview of issues in the literature and implications for teacher education. Cambridge Journal of Education, $39(2), 175-189$.

Benner, P. (1982). From novice to expert. The American Journal of Nursing, 82(3), 402-407.

Benner, P., Tanner, C., \& Chelsa, C. (Eds.). (2009). Expertise in nursing practice: Caring, clinical judgement and ethics (2nd ed.). Springer.

Bouchaud, M., Brown, D., \& Swan, B. (2017). Creating a new education paradigm to prepare nurses for the 21st century. Journal of Nursing Education and Practice, 7(10), 27-25.

Brady, D., Welborn-Brown, P., Smith, D., Giddens, J., Harris, J., Wright, M., \& Nichols, R. (2008). Staying afloat: Surviving curriculum change. Nurse Educator, 33(5), 198-201.

Braun, V., \& Clarke, V. (2013). Successful qualitative research: A practical guide for beginners. Sage.

Bridges, W. (2009). Managing transitions: Making the most of change (3rd ed.). Perseus Publishing.

Bridges, W., \& Mitchell, S. (2000). Leading transition: A new model for changes. Leader to Leader, 16, 30-36.

Canadian Nurses Association. (2013). Registered nurses: Stepping up to transform health care. https://www.cna aiic.ca/ /media/cna/files/en/registered_nurses_stepping _up_to_transform_health_care_e.pdf

Canadian Nurses Association. (2015). Framework for the practice of registered nurses in Canada.

Crawford, M. (2014). Transitioning the winds of change. Change Factory. https://www.changefactory.com.au/our-thinking/articles/transitioning-the-winds-ofchange/ 
Creswell, J. W. (2003). Research design, qualitative, quantitative, and mixed methods approaches. Sage.

Creswell, J. W. (2007). Qualitative inquiry \& research design: Choosing among five approaches (2nd ed.). Sage.

Crigger, N., \& Godfrey, N. (2014). From the inside out: A new approach to teaching professional identity formation and professional ethics. Journal of Professional Ethics, 30(5), 376382. https://doi.org/10.1016/j.profnurs.2014.03.004

Deane, W. (2017). Transitioning to concept-based teaching: A qualitative descriptive study from the nurse educator's perspective. Teaching and Learning in Nursing, 12(4), 237-241.

Denzin, N., \& Lincoln, Y. (2011). The Sage handbook of qualitative research. Sage.

Dewey, J. (1938). Experience and education. Free Press.

Duffy, R. (2013). Nurse to educator? Academic roles and the formation of personal academic identities. Nurse Education Today, 33(6), 620-624.

Duncan, K., \& Schulz, P. (2015). Impact of change to a concept-based baccalaureate nursing curriculum on student program outcomes. Journal of Nursing Education, 54(3), S16-S20.

Dyer, J. G., \& McGuinness, T. M. (1996). Resilience: Analysis of the concept. Archives of Psychiatric Nursing, 10(5), 276-282.

Giddens, J., Brady, D., Brown, P., Wright, M., Smith, D., \& Harris, J. (2008). A new curriculum for a new era of nursing education. Nursing Education Perspectives, 29(4), 200-204.

Giddens, J., Keller, T., \& Liesveld, J. (2015). Answering the call for a bachelors-prepared nursing workforce: An innovative model for academic progression. Journal of Professional Nursing, 31(6), 445-451.

Gobet, F., \& Chassy, P. (2008). Towards an alternative to Benner's theory of expert intuition in nursing: A discussion paper. International Journal of Nursing Studies, 45(1), 129-139.

Golden, J. (2016). An exploration of faculty transition to online teaching: The impact of identity disruption and participation in communities of practice on faculty satisfaction with online teaching [Doctoral dissertation, Northeastern University. Massachusetts]. DRS Digital Repository Service. http://hdl.handle.net/2047/D20207762

Gonzalez, M., \& Monereo, C. (2012). The nurse teacher. Construction of a new professional identity. Investigacion Y Educacion en Enfermeria, 30, 398-405.

Goodman, T. (2014). Nursing education moves to a concept-based curriculum. Nursing Education: AORN Connections, 99(6), C7-C8.

Hackel, L., \& Zaki, J. (2017). My brain contains multitudes: The value of a flexible approach to identity. Psychological Inquiry, 28(2-3), 99-102. ttps://doi.org/10.1080/1047840X.2017.1337387

Haegele, J., Hodge, S., Zhu, X., Holland, S., \& Wilson, W. (2020). Understanding the inclusiveness off integrated physical education from the perspectives of adults with visual impairments, Adapted Physical Activity Quarterly, 37(2), 141-159. 
Hanson, J. (2009). Displaced but not replaced: The impact of e-learning on academic identities in higher education. Teaching in Higher Education, 14(5), 553-564. https://doi.org/10.1080/13562510903186774

Holzberger, D., Philipp, A., \& Kunter, M. (2013). How teachers' self-efficacy is related to instructional quality: A longitudinal analysis. Journal of Educational Psychology, 105(3), 774-786. https://doi.org/10.1037/a0032198

Kantor, S. (2010). Pedagogical change in nursing education: One instructor's experience. Journal of Nursing Education, 49(7), 414-417.

King, M., \& Craik, R. (2019). Heriot-Watt university policy on block teaching. https://www.hw.ac.uk/uk/services/docs/learningteaching/policies/blockteachingpolicy.pdf

McNaughton, S., \& Billot, J. (2016). Negotiating academic teacher identity shifts during higher education contextual change. Teaching in Higher Education, 21(6), 644-658. https://doi.org/10.1080/13562517.2016.1163669

Miles, M., Huberman, A., \& Saldana, J. (2014). Qualitative data analysis: A methods sourcebook. Sage.

Miller, J. (2017). Managing transitions: Using William Bridges' transition model and change style assessment instrument to inform strategies and measure progress in organizational change management. Scholarship and Professional Work, 74, 1-9.

Patterson, L., Crager, M., Farmer, A., Epps, C., \& Schuessler, J. (2016). A strategy to ensure faculty engagement when assessing a concept-based curriculum. Journal of Nursing Education, 55(8), 467-470.

QRS International. (2018). NVIVO 12. https://www.qsrinternational.com

Repsha, C., Quinn, B., \& Peters, A. (2020). Implementing a concept-based nursing curriculum: A review of the literature. Teaching and Learning in Nursing, 15, 66-71.

Rogers, E. (2003). Diffusion of innovations (5th ed.). Free Press.

Sandelowski, M. (2010). What's in a name? Qualitative description revisited. Research in Nursing \& Health, 33, 77-84.

Smelser, N., \& Baltes, P. (Eds.). (2001). International encyclopedia of the social \& behavioral sciences. Elsevier.

Sword, T. (2012). The transition to online teaching as experienced by nurse educators. Nursing Education Perspectives, 33(4), 269-271.

ten Hoeve, Y., Jansen, G., \& Roodbol, P. (2014). The nursing profession: Public image, selfconcept and professional identity: A discussion paper. Journal of Advanced Nursing, 70(2), 295-309.

van Lankveld, T., Schoonenboom, J., Volman, M., Croiset, G., \& Beishuizen, J. (2017). Developing a teacher identity in the university context: A systematic review of the literature. Higher Education Research \& Development, 36(2), 325-342. 
Voogt, J., Pieters, J., \& Handelzalts, A. (2016). Teacher collaboration in curriculum design teams: Effects, mechanisms, and conditions. Educational Research and Evaluation, 22(34), 121-140.

Watkins, P. (2015). Mediating teachers as learners: Conversations from shared experience. Administrative Issues Journal, 5(2), 82-93. https://doi.org/10.5929/2015.5.2.3 